\title{
Laboreal
}

Volume $15 \mathrm{~N}^{\circ} 1 \mid 2019$

Trabalho e cooperação

\section{Cooperação e solidariedade em empreendimentos de economia solidária}

Cooperación y solidaridad en emprendimientos de economía solidaria

Coopération et solidarité dans des initiatives d'économie solidaire

Cooperation and solidarity in solidarity economy initiatives

Vanessa Andrade de Barros e Fabiana Goulart de Oliveira

\section{OpenEdition}

Journals

Edição electrónica

URL: http://journals.openedition.org/laboreal/986

DOI: $10.4000 /$ laboreal.986

ISSN: 1646-5237

\section{Editora}

Universidade do Porto

Refêrencia eletrónica

Vanessa Andrade de Barros e Fabiana Goulart de Oliveira, « Cooperação e solidariedade em empreendimentos de economia solidária », Laboreal [Online], Volume $15 \mathrm{~N}^{0} 1$ | 2019, posto online no dia 01 julho 2019, consultado o 10 dezembro 2020. URL : http://journals.openedition.org/laboreal/986 ; DOI : https://doi.org/10.4000/laboreal.986

Este documento foi criado de forma automática no dia 10 dezembro 2020.

Laboreal está licenciado com uma Licença Creative Commons - Atribuição-NãoComercial 4.0 Internacional. 


\section{Cooperação e solidariedade em empreendimentos de economia solidária}

Cooperación y solidaridad en emprendimientos de economía solidaria

Coopération et solidarité dans des initiatives d'économie solidaire

Cooperation and solidarity in solidarity economy initiatives

Vanessa Andrade de Barros e Fabiana Goulart de Oliveira

\section{NOTA DO EDITOR}

Manuscrito recebido em dezembro/2018

Aceite após peritagem abril/2019

\section{Introdução}

1 Nosso objetivo, neste texto, é mostrar como a cooperação e a solidariedade são construções e condições necessárias ao funcionamento e à eficiência dos processos produtivos. Buscaremos evidenciar que, mesmo nos empreendimentos da chamada Economia Solidária, onde a cooperação, solidariedade e autonomia seriam dados a priori, elas também são construídas no cotidiano das relações de trabalho e em meio a inúmeras contradições e conflitos que se evidenciam especialmente nas interfaces de aspectos técnicos e sociais ao longo do processo de produção. Nesse cenário, indicaremos como os conflitos são tratados nos diferentes arranjos organizativos, quais seus efeitos sobre a produtividade e suas implicações nas relações de cooperação estabelecidas entre trabalhadores.

2 Inicialmente, apresentamos alguns elementos analíticos a respeito da relação entre cooperação e solidariedade, que orientarão nossas reflexões, para, em seguida, tecer 
algumas considerações sobre a economia da dádiva, analisando sua importância como princípio e, ao mesmo tempo, como produto das relações de cooperação. Em continuidade analítica, discorremos sobre a economia solidária incluindo as cooperativas de catadores de materiais recicláveis. Nesse contexto, analisamos a parte visível do trabalho de triadoras de materiais, considerado o coração dos processos de reciclagem, no qual a cooperação é condição essencial para a eficiência do processo produtivo garantindo trabalho e renda às populações vulnerabilizadas econômica e socialmente. Apoiamo-nos nas reflexões teóricas a seguir e em resultados de pesquisas empíricas que realizamos em cooperativas de catadores de materiais recicláveis, onde utilizamos a abordagem etnográfica e a pesquisa-ação.

\section{Cooperação e solidariedade}

3 Ao buscarmos o sentido etimológico da palavra cooperação, encontramos sua origem no termo latino cooperare (cooperar). "Ato ou efeito de cooperar. Atuar, juntamente com os outros, para um mesmo fim; contribuir com trabalho, esforços, auxílio"; "colaboração e ação conjunta" (Houaiss \& Villar, 2001). No entanto, não é um termo de fácil compreensão dada a multiplicidade de situações que recobre, podendo designar tanto uma ação, uma teoria, um meio, uma finalidade quanto uma maneira de viver e de trabalhar juntos, dentre tantas outras possibilidades.

Encontramos sua utilização como sinônimo de colaboração, solidariedade, associação. Ela é também empregada em oposição às noções de competição, concorrência (Sato, Andrada, Evora, Neves, \& Oliveira, 2011). Refere-se, sobretudo, a uma escolha individual de participar em um coletivo, de compartilhar um projeto comum.

Para efeito deste texto, trataremos a cooperação como integrando um universo de valores que orientam a construção de um mundo comum de vida e de trabalho, incluindo-a no rol dos "valores sem dimensão" analisados por Schwartz e Durrive (2015, p.29): aqueles que não são mensuráveis, que não são compatíveis com avaliações por resultados, avaliações quantitativas de produtividade ou de rentabilidade, que são da ordem do viver juntos. Aproximamo-nos, assim, de Christoph Dejours (2012, p.39), segundo o qual: "a cooperação supõe um compromisso que é a um só tempo técnico e social. Isso se deve ao fato de que trabalhar não é, em tempo algum, apenas produzir: é também e sempre viver junto". Para compreendê-la como compromisso técnico e social a cooperação exige a análise da forma concreta que se apresenta no interior dos processos produtivos, circunscrevendo seu uso singular. Isto porque, nosso desafio é compreender como ações cooperativas solidárias em processos autogeridos se desenvolvem e expõem resultados em sociedades capitalistas heterogeridas, uma vez que, como sabemos, a cooperação está na base do processo de produção capitalista:

A atividade de um número maior de trabalhadores, ao mesmo tempo, no mesmo lugar (ou, se se quiser, no mesmo campo de trabalho), para produzir a mesma espécie de mercadoria, sob o comando do mesmo capitalista, constitui histórica e conceitualmente o ponto de partida da produção capitalista" (Marx, 1983, p.257).

Entendemos que esse recorte é importante na medida em que trabalhar e viver juntos implica a realização de trocas - simbólicas e econômicas- o que nos remete aos estudos 
de Marcel Mauss (1974) sobre a dádiva, sobre trocas que se distinguem das trocas exclusivamente econômicas, mas que coexistem com as economias mercantis.

7 Assim é que dar, receber e retribuir são para este autor o fundamento das relações sociais, configurando o campo da solidariedade, que se constitui ao mesmo tempo como base e resultado de processos cooperativos.

8 Segundo Martins (2005, p.45), "a teoria da dádiva, vem sendo resgatada como um modelo interpretativo de grande atualidade para se pensar os fundamentos da solidariedade e da aliança nas sociedades contemporâneas", uma vez que tal teoria não se restringe às relações não mercantis, estando presente em todas as relações. Desse ponto de vista, ela nos ajuda a compreender a solidariedade concreta, que se constrói no cotidiano do trabalho e que vai além de um simples adjetivo ou um imperativo normativo.

9 De fato, a solidariedade é também um valor sem dimensão (Schwartz \& Durrive, 2015), pois pertence à esfera da vida singular e social. Ela se apresenta como parte da atividade humana que produz o mundo, constrói relações, promove a circulação de afetos e insere o sujeito numa rede de vínculos que permite a sua própria produção. Assim como o dom, ela não é prescrita em normas.

$10 \mathrm{O}$ apelo à solidariedade como fenômeno massificado pelas campanhas da mídia não é novo. A crítica ao economicismo, em especial aos agentes econômicos que racionalmente otimizam recursos e sempre agem buscando seus próprios interesses, já havia levado ao reconhecimento de outras relações econômicas ou, mais propriamente, sociais, que não se reduzem ao comportamento do homem econômico racional. Efetivamente, relações de confiança, parcerias entre empresas concorrentes e, de modo geral, relações de troca que não se medem por valores monetários não são exclusivas de épocas pré-capitalistas, de sociedades tradicionais não regidas por relações econômicas racionais. Em uma primeira aproximação, é forçoso reconhecer que essas relações sociais, não imediatas ou exclusivamente econômicas, sempre coexistiram com as trocas econômicas, mesmo nas economias mercantis e permanecem na atualidade. Elas não se restringem a coisas do passado; as antigas formas de constituição dos vínculos sociais se mantêm mesmo na lógica mercantil moderna, como apontado por Mauss (1974).

11 Em nossa experiência de mais de quinze anos atuando na assessoria a empreendimentos da chamada Economia Solidária, especialmente junto aos catadores de materiais recicláveis, ouvimos inúmeras vezes os trabalhadores afirmarem que "o problema do empreendimento é a falta de solidariedade". Ou ainda: "alguns cooperados não são solidários". A solidariedade é concebida por eles, muitas vezes, como um valor quase natural, e não uma construção que se desenvolve na prática do trabalho.

12 Nesse caso, a economia da dádiva é uma referência importante que nos permite compreender a solidariedade como um processo em desenvolvimento, uma construção prática, que dificilmente, em sua diversidade, se deixa apreender por conceitos a priori. Nossa posição é que não se organizam os empreendimentos da economia solidária a partir de uma definição prévia do que é solidariedade. Para nós, a solidariedade se forma a partir das práticas dos produtores associados. Essa inversão é típica do militantismo utópico. Na vida real, são os empreendimentos existentes que definem a solidariedade possível, tendo como base a história de cada um, como podemos observar também nas pesquisas citadas por Magni e Gunther (2014) em três associações de 
catadores de materiais recicláveis, considerando aspectos das relações interpessoais e os princípios cooperativistas da solidariedade.

\section{Economia da dádiva: base de solidariedade e da cooperação}

13 É certo que a economia da dádiva readquiriu força neste fim de século, em parte devido ao crescimento da chamada "economia solidária", que desperta interesse enquanto fenômeno empírico e enquanto modelo de organização social, sustentada em princípios e relações de cooperação e trocas, que subsumem o econômico ao humano-social. Nessas experiências solidárias, as trocas entre os homens já não se regem apenas pelas medidas e valores monetários, mas por medidas e valores sociais, como a dádiva, cuja dinâmica não obedece a normas de equivalência econômica. Como nos mostra Marcel Mauss (1974), os presentes trocados servem de suporte para estabelecimento de relações pessoais, ao mesmo tempo desinteressadas e obrigatórias, pois o dom implica o contra dom: devolver ou prestar serviço a quem o presenteou, o que vem a estabelecer uma sociabilidade solidária.

Os estudos de comunidades pré-capitalistas mostram que o dom sempre existiu e existe em todo lugar, embora não seja igual em toda parte. Ele se caracteriza, em oposição ao mercado, pela ausência de cálculo e de contabilidade, ao passo que o mercado se apresenta como o lugar das relações de interesses, da contabilidade, e, em oposição ao Estado, que é o espaço da obediência e respeito às leis, onde todos são iguais. 0 dom pressupõe a liberdade e a espontaneidade (Godbout,1992).

Mauss (1974) identifica as relações sociais fundamentadas em três elementos: dar, receber e retribuir. Toda dádiva, todo presente, cria em quem recebe a obrigação de retribuir e, assim, se estabelece um vínculo social entre doador e receptor, o que faz com que os objetos circulem. É através da circulação que os objetos ganham valor e retornam à sua origem, retribuindo ao seu doador. A dádiva, portanto, estaria ligada a um complexo sistema de trocas que vincula doador e receptor. Essa rede de trocas é a solidariedade, cujo princípio geral é de que todo dom deve ser retribuído com um contradom de valor igual ou maior. A transferência de um dom é um meio de instituir uma relação de dependência recíproca, que acarreta consequências sociais para os protagonistas - obrigações, mas também vantagens.

o movimento das trocas permite que os dois parceiros criem dívidas um com o outro que ora se equilibram, ora se distanciam, mas é nesse movimento que se estabelecem laços. Logo, "o dom e o contradom são a maneira mais simples de produzir dependência e solidariedade" (Godelier, 2001, p.156). As trocas teriam, portanto, a função de criar vínculos entre os seres humanos e entre os grupos, e esses vínculos é que garantem a sobrevivência e a reprodução de uma comunidade.

17 Essa perspectiva solidária é um dos fundamentos das organizações cooperativas e das associações de trabalhadores, que buscam criar relações baseadas na solidariedade no interior do sistema capitalista de produção. Nessas organizações, desenvolvemos pesquisas cujos resultados orientam nossas reflexões.

18 Nas cooperativas de catadores, conforme mostraremos a seguir, os vínculos sociais se mostram na construção de arranjos que buscam atender, ao mesmo tempo, as necessidades do coletivo e as especificidades de cada sujeito. Esses arranjos se 
configuram como trocas que se estabelecem com base em valores não mercantis. Um exemplo pode ser observado na aplicação das regras. Embora sejam importantes para assegurar o funcionamento do empreendimento e também certa coesão do grupo, sua aplicação exige cuidado e, em alguns casos, flexibilidade. Os catadores reconhecem que não é possível tratar a todos da mesma forma, que a aplicação das regras não se faz escudando-se exclusivamente em uma racionalidade técnica, mas singularizando as situações individuais. Essa necessidade de flexibilizar as regras, para que todos possam participar de acordo com sua condição - idade, saúde, conhecimento - advém de uma "experiência prática, que se apresenta como determinante para o funcionamento e a produtividade do trabalho nas cooperativas de reciclagem. Ela é que permite o desenvolvimento de habilidades e modos operatórios necessários para responder às exigências da atividade" (Mata, Oliveira, \& Barros, 2017), conforme discutiremos a seguir.

\section{Economia solidária}

No Brasil, a expressão economia solidária tornou-se mais conhecida nos anos 1990, à medida que iniciativas econômicas surgiram e foram reconhecidas por sua natureza associativa e suas práticas de cooperação e autogestão (Gaiger, 2013). O conceito de economia solidária, por sua vez, refere-se a práticas muito variadas, que trazem dificuldades conceituais, conforme já tratamos em trabalhos anteriores (Oliveira, 2010). Concordamos com Wellen (2012), quando aponta uma "insuficiência teórica" acerca do termo "economia solidária" que, segundo ele, "não possui substrato teórico e político capaz de fornecer fundamentos de pesquisa precisos" (p.20). Valemo-nos aqui dessa noção para estabelecer uma diferenciação entre empreendimento solidário $\mathrm{e}$ experiências tradicionais mercantis - orientadas pela racionalidade de "[...] produzir para acumular, acumular para dominar"(Cattani, 2009, p.177) - fazendo incidir o foco de nossas análises sobre aspectos concretos da atividade de trabalho nestes empreendimentos.

O desenvolvimento da economia solidária, objetivada especialmente pela construção de cooperativas e associações de trabalhadores, relaciona-se ao contexto de crise econômica ampla que afeta não só as diferentes economias do mundo, mas também as bases do mecanismo histórico de regulação das sociedades na modernidade, marcadas pela sinergia entre estado e mercado. Ela tem por vocação combinar uma dimensão comunitária, mais tradicional, com uma dimensão pública, mais moderna em sua ação.

21 No caso das cooperativas de produção e prestação de serviços, a dimensão pública se apresenta na medida em que a organização se produz a partir de uma problemática de geração de trabalho e renda. Além de sua ação no mercado, cujo benefício social, a princípio, restringe-se apenas ao grupo dos cooperados internos - o que por si só já difere da lógica capitalista em razão da apropriação coletiva dos ganhos - a tendência do movimento é de valorização de uma dimensão pública da sua ação mediante a ênfase nos impactos da organização na vida local (França Filho \& Laville, 2004).

22 A economia solidária aparece, assim, em uma perspectiva de busca de novas formas de regulação da sociedade - a auto-organização social - envolvendo ações ao mesmo tempo econômicas e políticas. Dentre as várias formas de interpretação dessa proposta, existem aquelas que enxergam nessas experiências uma possibilidade do surgimento de uma outra economia, capaz de substituir o mercado capitalista para criar o mercado 
solidário, ou seja, submeter o capitalismo às regras de solidariedade (Singer, 2002). Outras perspectivas (França Filho, 2013; França Filho \& Laville, 2004) consideram a possibilidade de fazer emergir um "terceiro setor" regido pela dádiva, sem a supressão do mercado e do Estado. Trata-se, aqui, de uma visão liberal e funcionalista que limita a ideia de economia solidária a uma demanda funcional, que teria o papel de ajustamento social, corrigindo as lacunas deixadas pelo mercado e pelo estado.

Concordamos com Laville (2004) quando argumenta que a divisão da vida moderna se apresenta, na economia, através de um duplo movimento: por um lado, mantém a separação entre esfera pública e privada; por outro, tenta juntar esses dois polos localizando as iniciativas de economia solidária nesta segunda posição. Segundo esse autor, tais iniciativas tentam associar a questão social à auto-organização popular, esboçando o projeto de uma economia fundamentada na solidariedade, que não se traduz em benevolência ou solidariedade idealizada num sentido unidirecional, mas em reciprocidade onde se constroem os vínculos sociais.

\section{Apresentação metodológica}

As reflexões propostas neste artigo têm como base empírica estudos realizados em dois empreendimentos de catadores. Ambos foram pesquisados simultaneamente, em dois períodos distintos: julho de 2009 a maio de 2010 e, depois, de outubro de 2012 a novembro de 2013. Em ambos os períodos, utilizou-se o método etnográfico, baseandose na pesquisa-ação (Dubost \& Lévy, 2002) e na grouded theory (Tarozzi, 2011).

O método etnográfico propõe uma imersão do pesquisador na cultura que ele estuda, de modo que seja capaz de "impregnar-se" dos temas e questões vivenciados nessa sociedade, seus ideais, suas angústias (Laplantine, 1994). Ao invés de conhecer uma sociedade apenas em suas manifestações exteriores, essa abordagem busca interiorizar a significação que os próprios indivíduos atribuem a seus comportamentos.

26 A pesquisa-ação associa a pesquisa à ação. Busca-se construir dispositivos que facilitem as trocas entres os envolvidos (pesquisadores e demais atores/nativos) por intermédio das suas percepções, representações e dos sentimentos, por vezes desconhecidos, reprimidos, ou simplesmente silenciados. Essa abordagem permite que os atores compreendam melhor o significado das situações vividas e a parte que nelas ocupam, estimula a construção de respostas para os problemas identificados, mobilizando a energia para essa finalidade (Dubost \& Lévy, 2002).

Já a grounded theory, também conhecida como teoria fundamentada em dados, busca construir categorias analíticas a partir dos dados, seguindo as indicações que provêm do fenômeno. A natureza desta metodologia fundamentada na realidade confere ao conhecimento, que é produzido a partir dela, um valor prático-operativo e útil para os operadores (Tarozzi, 2011 p.13).

28 Durante a pesquisa, foram realizadas observações empíricas e entrevistas na situação de trabalho em que os catadores estavam envolvidos e, por algumas vezes, nós também fizemos a triagem na esteira, junto com as triadoras. Essa experiência, que nos possibilitou receber suas instruções, permitiu uma compreensão maior acerca dos elementos que envolvem a atividade de triagem.

Trataremos, neste texto, da pesquisa realizada em 2012/2013 (Oliveira, 2016). Durante 14 meses, dois dias por semana, ficávamos junto aos catadores, no empreendimento. 

desenvolvem atividades de coleta, separação, prensagem, carregamento e comercialização dos recicláveis. A gestão das cooperativas é realizada exclusivamente por catadores que elegem, entre eles, uma equipe coordenadora a cada dois anos. Em uma delas, a coleta dos materiais é feita somente por cooperados que utilizam caminhões. Na outra, a coleta é feita, num primeiro momento, por cooperados que utilizam carrinhos próprios e, em outro, os materiais são reunidos e transportados até o galpão pelo caminhão da prefeitura.

31 Nos dois empreendimentos, a maior parte dos materiais processados são oriundos da coleta seletiva porta a porta, realizada nos bairros, embora existam, também, materiais coletados em empresas grandes geradoras de resíduos. Esses materiais compreendem não só diversos tipos de papel, plásticos, alumínio, ferro e vidro, mas também resíduos orgânicos, como restos de alimentos, cascas, folhas, e rejeitos como fraldas, fezes e papel higiênico, que se encontram misturados aos materiais recicláveis.

A triagem, etapa que recebeu maior atenção neste estudo, consiste na separação manual dos materiais coletados. Ela é a principal responsável pela agregação de valor aos materiais que são comercializados. Em um dos empreendimentos, funciona em dois turnos. 0 primeiro de $6 \mathrm{~h}$ às $14 \mathrm{~h}$; o segundo de $14 \mathrm{~h}$ às $22 \mathrm{~h}$. É realizada sobre uma esteira rolante, onde 12 triadoras se alternam diariamente variando as posições que ocupam nesse equipamento. Em cada posição, a triadora é encarregada de coletar três ou quatro tipos distintos de materiais. No outro empreendimento, a triagem é feita em bags sacos de aproximadamente mil litros - por 13 triadoras que devem cumprir uma meta diária de triagem de 12 bags.

Os resultados da produção, nos dois empreendimentos, são distribuídos em partes iguais entre os cooperados, sendo descontadas as faltas. No segundo empreendimento, o valor depende ainda do cumprimento das metas e aqueles que não as atingem têm o valor abatido.

\section{As cooperativas de catadores de materiais}

O atual modelo de reciclagem no Brasil deve sua amplitude à situação de pobreza de grande parte da população, que se submete às condições precárias de trabalho e, a partir delas, transforma lixo em riquezas, constrói valores e possibilidades de vida em comum.

Isso porque, como afirma Sennett (2012), a cooperação e a construção de comunidades cooperativas podem ser uma oportunidade de vida para os excluídos da ordem econômica que proporcionaria ultrapassar as limitações que lhes são impostas.

De fato, a base comum para a formação das associações e cooperativas de catadores é a situação de precariedade dos seus membros, historicamente vulnerabilizados e não possuindo os requisitos compatíveis com as exigências do mercado formal. São trabalhadores abandonados à própria sorte, que não encontram lugar na nova configuração econômica mundial, sendo levados a criar outras formas de sobrevivência, muitas vezes marginal (Barros \& Silva, 2017). Constituem-se por pessoas com baixo nível de escolaridade, moradores de rua (Magni \& Gunther 2014), usuários de drogas, ex-presidiários e outras pessoas com perfis pouco atrativos ao mercado formal de 
trabalho, que encontram na atividade com os recicláveis uma forma de obter renda e de se desenvolver como trabalhadores.

O trabalho nas cooperativas se apresenta assim para essas pessoas como uma das poucas oportunidades de renda, cujo valor, por sua vez, depende da capacidade de produção do coletivo. Essas organizações possuem uma estrutura complexa, em que diversos aspectos de natureza técnica, econômica, política e social estão entrelaçados e influenciam uns aos outros.

A noção de liberdade é uma tradução interessante de tal complexidade: nas empresas capitalistas, a liberdade se caracteriza pela possibilidade de rompimento do vínculo ou do contrato a qualquer momento; nas cooperativas, ela se constitui como possibilidade de negociação e transformação das condições de trabalho, orientadas para a manutenção dos vínculos. Para tal, cooperativas desenvolvem arranjos que consideram, dentro de certos limites, as diferenças individuais e a história de cada um - mudança no horário de trabalho em função da escola e mudança de função devido às limitações físicas decorrentes da idade, do adoecimento ou da gravidez. A flexibilidade no trabalho, a paciência, ajudam a preservar os vínculos, e permitem que as pessoas se transformem - "de repente, a pessoa fica bom de serviço" (fala de uma catadora sobre o trabalho na cooperativa). Como já observamos em estudos anteriores (Mata et al., 2017, p.365.), "a experiência de trabalho envolve a produção de um saber que transforma o sujeito, e o constitui como trabalhador, conformando o seu corpo, sua percepção, suas normas e valores, sua relação com o mundo".

Nas cooperativas, as decisões são construídas apoiando-se num coletivo. Uma cooperada, referindo-se à admissão/demissão de associados, diz: "Você não vira pra ele simplesmente e fala a partir de hoje você não é mais cooperado. Ainda que o grupo julgue alguém como leviano, deve-se escutá-lo: "Vai ter que sentar, conversar, falar: fulano, tá assim, assado, e aí?”. As estratégias utilizadas priorizam o diálogo, mesmo que sejam muitas vezes acompanhados por brigas ou atos de rebeldia.

Essa forma de gestão permite que o grupo institua um certo controle social sobre seus membros, controle que é necessário para organizar e coordenar a produção e, ao mesmo tempo, desenvolver competências comunicacionais, que fortalecem formas de relações mais democráticas. Nas cooperativas, os trabalhadores afirmam que "aprendem a conversar", o que implica aprender a negociar, construir alternativas coletivas, ter paciência.

Dejours (2012, p.89) aponta:

Cooperar é procurar compatibilidades entre instâncias. Uma instância pode, em uma determinada perspectiva conceitual, ser constituída por um colega, um subordinado, um chefe, um objeto técnico, ou um cliente. Oferecer uma contribuição à cooperação consiste em ajustar seu próprio modo operatório, de maneira que ele esteja adequado com o funcionamento das demais instâncias com as quais cada operador está em relação direta, sejam elas humanas ou "maquínicas".

Podemos dizer que as cooperativas de catadores convivem com um duplo desafio. Por um lado, têm que aumentar a produtividade e eficiência da coleta e processamento dos materiais recicláveis e, dessa forma garantir renda para seus associados; por outro, devem incluir pessoas excluídas do mercado formal de trabalho - geralmente por não possuírem escolaridade, formação, competências e habilidades exigidas - e que estão 
em situação de vulnerabilidade social e marginalização. Para isso, não podem reproduzir a mesma lógica excludente do mercado capitalista, sendo necessário recriar arranjos que atendam suas necessidades de produção, de geração de renda e que sejam compatíveis com suas necessidades humanas e de inclusão.

É nesse contexto que desenvolvem uma lógica baseada na solidariedade, que vai além dos processos produtivos, influenciando a construção de sociabilidades solidárias por meio do trabalho. Como já demonstramos em trabalhos anteriores (Mata et al. 2017, Oliveira, 2016, Barros \& Pinto, 2008), a aprendizagem de uma prática depende do engajamento do sujeito na comunidade.

De fato, embora o enfrentamento do desemprego seja uma das principais razões para a constituição dos empreendimentos solidários (Faria, 2009), o trabalho nessas cooperativas produz uma forma de sociabilidade em que o emprego se torna não mais um fim em si mesmo, mas um meio de se vincular a um projeto coletivo concreto (França Filho \& Laville, 2004) o que evidencia igualmente a dimensão política dos empreendimentos: "Participar do movimento associativo constrói uma identidade política e cria sociabilidades baseadas na solidariedade e na existência de um projeto comum de transformação das relações de exploração e opressão" (Barros \& Pinto, 2008, p.76).

Uma expressão dos catadores ilustra esse contexto: “Aqui, a gente vem primeiro pela necessidade, mas você fica pelo amor". Assim, eles sinalizam um processo de transformação que é produzido por meio dos vínculos sociais que operam no trabalho. Essa transformação envolve aspectos sociais e subjetivos presentes na construção de um projeto coletivo, que se desenvolve na medida em que os trabalhadores se apropriam do trabalho. Este é o elemento central do processo que arbitra acerca da criação das regras e dos valores do grupo.

É preciso destacar que a cooperação, assim como o espírito cooperativo ou solidário que tanto se reivindica nas cooperativas não são valores constitutivos da personalidade dos trabalhadores, nem dados a priori, mas são construídos na atividade. Como veremos, a cooperação é uma exigência imposta concretamente no trabalho. Trata-se, portanto, de uma condição para o desenvolvimento da atividade, que, dessa forma, cria condições para o surgimento de habilidades individuais e estratégias coletivas.

47 Os catadores enfatizam que cada um deve receber por aquilo que produz e ninguém pode trabalhar para o outro. A complexidade dessa questão reside especialmente no limite de cálculo. Não é possível saber, com certeza, se uma pessoa trabalha mais ou menos que outra, ou quando ela está "morcegando" - vocábulo utilizado pelos trabalhadores para designar aqueles que não trabalham, ou que "enrolam", fingindo trabalhar. Se consideradas as diferenças fisiológicas, técnicas, sociais, morais, econômicas, históricas, não existem formas de medir e comparar o esforço de um e de outro.

48 Embora a lógica de equivalência do mercado esteja na origem dos conflitos, é a economia da dádiva, na qual as trocas não se medem por valores mercantis, que permite encontrar arranjos e soluções que atendam às necessidades dos trabalhadores. Os processos de produção e os sistemas de remuneração criados em cada empreendimento evidenciam tais situações.

49 O faturamento dessas cooperativas depende quase exclusivamente da comercialização dos materiais. Desse modo, a produtividade destes empreendimentos se reflete 
diretamente na renda dos associados, o que, por sua vez, influencia o engajamento para o trabalho e, além disso, é fonte de conflitos e "indisciplinas" (absenteísmo, "morcegagem", fraudes). As cooperativas buscam lidar com essas dificuldades por meio da criação de regras e controles que visam compatibilizar as necessidades de produção às possibilidades de contribuição coletivas e individuais.

50 A princípio os conflitos se resolvem pela criação de metas que devem ser cumpridas, a despeito do ritmo de cada um. $O$ uso da esteira, por sua vez, dispensa as metas e tenta estabelecer um ritmo de trabalho, que é, no entanto, controlado pelos trabalhadores que podem pará-la quando precisam de mais tempo para pegar os materiais. Embora se constitua em um instrumento de controle utilizado na produção capitalista como chicote para impor um ritmo (Moraes Neto, 1991), na cooperativa, a esteira tem sua função recriada pelos trabalhadores, que a utilizam ora como instrumento facilitador da produção, um simples transportador de materiais, ora como mecanismo de regulação do trabalho coletivo.

51 Essa função ambivalente é significativa em relação ao grau de solidariedade e cooperação existente nos empreendimentos. Para evitar que alguns associados "morceguem" ou "enrolem", aciona-se a esteira, mas, quando alguém da equipe está sobrecarregado, o movimento é interrompido. Essa necessidade de recorrer ao movimento da esteira para impor uma contribuição mínima ao trabalho coletivo indica o limite da autogestão, quando se torna necessário valer-se de mecanismos capitalistas de controle. Ao contrário, quando a esteira é parada por uma decisão coletiva, a partir da solicitação de uma trabalhadora, começam a ser desenvolvidos outros processos sociais de regulação da carga de trabalho.

Ainda que não sejam empresas capitalistas, esses empreendimentos se estabelecem sob a hegemonia do capital e, por conseguinte, reproduzem os conflitos da lógica privada da exploração, como analisa Lima (1997, p. 176):

Quando falamos de lutas de classes, não estamos pensando apenas nos processos históricos e muito menos em política partidária, mas em fatos que se passam no cotidiano da vida no trabalho. Em cada gesto de trabalho, em cada peça trabalhada, está presente a contradição fundante da forma de sociabilidade capitalista. Por isso, não pode haver nem consenso nem autonomia dos trabalhadores, pois o controle do capital sobre o trabalho é condição necessária para ampliar a extração da mais-valia. O conflito de interesses não é momentâneo, ou devido ao autoritarismo das chefias, mas estrutural, isto é, radica-se na própria relação de venda e compra da força de trabalho.

53 Taylor, Ford e outros fracassaram ao tentar mensurar o trabalho, acreditando que assim poderiam eliminar os conflitos. Em suas análises, Lima (1997, p. 178.) identifica que a origem desses conflitos está na contradição da produção capitalista.

Quando modernos ergonomistas tentam, através de sua parafernália tecnológica, medir carga de trabalho e estabelecer 'em bases científicas', pausas e ritmos, apenas continuam perseguindo a fórmula mágica que resolveria de uma vez por todas, a contradição fundamental da produção capitalista: com que intensidade se deve utilizar, durante um dia, a força de trabalho. 

como o coração do processo de produção de recicláveis. É também o setor onde podemos observar e compreender com maior clareza a constituição de vínculos de solidariedade e de cooperação entre as triadoras, traduzidos pelos arranjos e estratégias organizativas como uma exigência do processo de trabalho para se obter maior eficiência. centrais automatizadas comecem a surgir. Sendo uma atividade predominantemente manual, ela é baseada na força de trabalho humano e é a etapa da cadeia produtiva que requer maior aproximação ou contato das trabalhadoras com os materiais. Essa etapa ocupa grande parte da mão de obra das cooperativas - em torno de $50 \%$, dependendo do arranjo organizativo - e, em sua maioria, ou quase totalidade, é realizada por mulheres, razão pela qual utilizamos aqui a forma feminina para nos referirmos a essas trabalhadoras.

Visto de longe, o trabalho de triagem ou separação de materiais parece simples, o que justificaria sua destinação a pessoas "sem qualificação" ou mesmo sua substituição por máquinas. Entretanto, sob a perspectiva da atividade (Schwartz 2007, Clot \& Lhuilier, 2010), outros elementos se apresentam e, como tentaremos mostrar, a atividade de triagem se revela como algo complexo, que requer um conjunto de competências inscritas sobre um plano comum de solidariedade e desenvolvidas na prática, sustentando-se na cooperação estabelecida entre as triadoras, ainda que permeada por conflitos e desavenças.

Enquanto sistema sociotécnico, a triagem não pode ser analisada sem articular processos técnicos de trabalho e relações sociais. A questão no que diz respeito à forma de triagem mais eficiente (duas etapas ou uma, esteira, bancada, silo, chão), ainda permanece sem resposta e deverá ser objeto de pesquisas mais específicas. Essas opções, aliás, são fonte de muitas controvérsias entre os catadores e gestores públicos que tentam impor um modelo único de organização às cooperativas, desconsiderando as dimensões sociais relacionadas à sua história e ao perfil dos associados (idosos, mulheres, portadores de deficiência).

60 Na prática, se considerarmos as relações entre o processo técnico e as relações sociais (entre o subsistema técnico e o subsistema social, nos termos da sociotécnica), a questão relacionada ao sistema de produção "mais eficiente" se torna complexa, de fato, insolúvel, se formulada fora dos nexos sociais. Com efeito, como comparar uma 
cooperativa de pessoas mais jovens, que preferem trabalhar com esteira, a uma outra, com pessoas mais idosas ou deficientes, ou em sofrimento mental, que optaram por trabalhar com postos de triagem improvisados no chão? Impor um modelo único significa arriscar-se a passar por cima desses arranjos, que, às vezes, propicia ótimos locais, dadas as circunstâncias e especificidades de cada associação.

61 Concretamente, o trabalho de separação dos recicláveis consiste em (re) estabelecer classificações para os diversos materiais descartados como lixo. Dizemos "estabelecer" e "reestabelecer" a fim de acentuar a característica dinâmica e situada da atividade de triagem. Não se trata apenas de separar materiais seguindo uma classificação preestabelecida - o que pode ser feito por uma máquina automática. Trata-se, sim, de categorizar, considerando critérios de utilidade (sujidade, reutilização, reciclabilidade) e econômicos (preço de mercado, custo da separação, valor relativo dos materiais), que podem variar no espaço e no tempo. Tudo isso se realiza com maior ou menor complexidade, em cada gesto de triagem.

Os conflitos entre algumas triadoras que atuam nas cooperativas mostram que a atividade dessas profissionais requer o desenvolvimento de diversas habilidades no nível das capacidades corporais, sensoriais, motoras e psicossociais. E, dependendo das condições em que ela se realiza (disponibilidade de infraestrutura, grau de educação da população, exigências estabelecidas pela prefeitura, condições de mercado), essa atividade se torna ainda mais complexa e dependente de cooperação entre as trabalhadoras.

63 A aprendizagem da atividade das triadoras se desenvolve, em princípio, por meio da observação das mais experientes e das instruções que delas recebem. Durante o trabalho, triadoras experientes, posicionadas mais próximas das novatas, se encarregam de orientar os gestos destas últimas, oferecendo-lhes dicas e sugestões relacionadas ao que elas devem fazer para realizar o trabalho e preservar o corpo. Por exemplo: aproximar-se mais da esteira de maneira a facilitar o acesso aos materiais; utilizar um estilete para abrir as sacolas em vez de rasgá-las; furar as garrafas, em vez de desenroscar as tampas para retirar o ar; molhar as espirais dos blocos de papel para facilitar a retirada das folhas.

As triadoras fazem questão de se lembrar das colegas que lhes ensinaram o ofício quando elas entraram na cooperativa, o que evidencia, mais uma vez, os vínculos construídos por meio da economia da dádiva. Afirmam que o início é difícil e acreditam que, para aprender, é preciso ter "força de vontade", que elas são "empurradas" inicialmente pela necessidade. Avaliam que muitas pessoas são atraídas pela renda que, no caso das duas cooperativas é relativamente elevada, se comparada ao que elas conseguiriam obter em outro trabalho com o nível de escolaridade que possuem. Entretanto, quando começam a trabalhar e percebem as dificuldades, algumas desistem e não voltam.

Há situações em que as triadoras experientes parecem submeter as novatas a uma espécie de prova ou "ritos de iniciação", expondo-lhes ratos, baratas, objetos malcheirosos ou oferecendo alimentos encontrados no material. Uma triadora experiente explica que o grupo não pode manter as pessoas que têm nojo ou medo da sujeira. Isso porque esses elementos fazem parte do trabalho. Aqueles que não os suportam ou não enfrentam esses elementos não podem trabalhar na cooperativa porque "uns não podem trabalhar para os outros", como argumenta uma das associadas. 

separam os objetos neles contidos, depositando-os nos compartimentos estabelecidos para cada material. As mais experientes são capazes de identificar alguns conteúdos, antes mesmo da abertura dos sacos e, assim, conseguem antecipar movimentos, seja no sentido de se prevenirem de objetos perigosos ou contaminantes, abrindo o saco com mais atenção, ou rejeitando-o, seja no sentido de otimizar o processo de produção, despejando o conteúdo do saco num local específico a fim de que os objetos não se misturem ou não contaminem os demais, como no caso de matéria orgânica.

69 A triagem de alguns lotes é reconhecidamente mais penosa que a de outros. Os produtos oriundos de laticínios ou frigoríficos, por exemplo, costumam ter um cheiro desagradável e, dependendo das condições em que são armazenados, acumulam vermes, o que torna esse processo ainda mais difícil. Alguns odores se impregnam na pele e permanecem mesmo após o banho. Nesses casos, o sistema de revezamento, tanto na esteira, quanto no processo de triagem em bags, é a forma encontrada pelas triadoras para equalizar os esforços ou a penosidade exigida em cada tarefa.

$70 \mathrm{Na}$ esteira, as posições são rotativas durante a semana. Mesmo que algumas trabalhadoras tenham preferência por uma posição, elas devem trabalhar em todas, sendo cada dia em uma diferente. Na cooperativa em que a triagem é realizada em bags, os lotes de materiais considerados mais difíceis são triados no sistema de revezamento. Existem também situações em que o grupo avalia que idosos, mulheres grávidas ou pessoas com saúde fragilizada não devem participar do revezamento ou que devem ter prioridade na triagem de materiais mais limpos, sem que isso prejudique a renda desses trabalhadores. Nesses casos, a decisão é tomada e assumida coletivamente pelos trabalhadores.

71 Existem, também, estratégias coletivas de cada grupo que, além de facilitar o trabalho individual, estabelecem um tipo de proteção aos trabalhadores. Isso acontece na triagem de materiais que elas identificam como perigosos - pó oriundo de fábricas; resíduos hospitalares - ou lotes que contenham uma quantidade maior de objetos que despertam nojo ou mau cheiro, como plásticos sujos de carne ou sangue, latas misturadas a vômitos ou fezes. As triadoras advertem umas às outras sobre o material, desprezam alguns objetos, mesmo que eles tenham valor de mercado, escolhem, 
quando possível, o melhor momento do dia para triá-los, ajudam as colegas a triar, mesmo que não estejam escaladas para tal atividade.

Como as situações que envolvem os resíduos, o mau cheiro ou nojo são também objeto de conflitos entre as cooperativas e a população do seu entorno, geralmente as cooperativas são instaladas em regiões pouco nobres da cidade, longe dos centros urbanos. Tais conflitos aumentam as exigências da atividade - intensificação do ritmo de trabalho no sentido de reduzir o estoque de materiais não triados, melhoria dos aspectos visuais da organização - evitando a hostilidade e as ameaças feitas pela vizinhança incomodada pelo mau cheiro, pela presença de bichos, pelo barulho, pela "má aparência" do espaço e das pessoas que por ali circulam. As relações de cooperação, nesse caso, extrapolam os muros da cooperativa e se estendem pelo território.

73 A experiência prática das triadoras, que incorpora o modo de cooperação específico de cada grupo, apresenta-se como determinante para o funcionamento e a produtividade das cooperativas em qualquer situação. Ela é que permite o desenvolvimento de habilidades e os modos operatórios necessários para responder às exigências da atividade e das comunidades do entorno.

O sistema com esteira de triagem que se desenvolve na cooperativa estudada é equivalente à linha de montagem criada por Ford no início do século XX. Ela se constitui em um mecanismo que controla o ritmo de trabalho, obrigando todos os trabalhadores a realizarem suas tarefas em uma mesma cadência. No entanto, as próprias triadoras reconhecem que há diferenças na capacidade de produção de uma e de outra e em dias diferentes. "Não é todo dia que a gente está bem-disposta- diz uma triadora. Elas acreditam que não podem cobrar muito das colegas quando observam que não estão trabalhando bem, mas tentam estimulá-las para produzirem o máximo.

75 A produtividade na esteira exige uma ação coordenada das integrantes e cada triadora é responsável por pegar um, dois ou até sete tipos de materiais, o que depende da posição de cada uma e do número de operadoras presentes no momento. Às vezes, algumas faltam ou saem para ir ao banheiro ou atender um comprador. Nesses casos, elas devem comunicar sua ausência às demais e pedir que alguém assuma o seu posto. 0 rodízio de posição/função na esteira obriga que todas aprendam a trabalhar em todas as posições e evita a repetição do trabalho.

As triadoras posicionadas no início da esteira são responsáveis por abrir os sacos e pegar os plásticos brancos, mistos, as sucatas e o alumínio. A que se posiciona em seguida também pega os papelões grandes e, como ela fica mais próxima do painel de controle, é responsável por controlar a velocidade da esteira, parando-a quando solicitado por alguma triadora ou na medida em que ela mesma percebe que é necessário - por exemplo, quando ela não consegue rasgar muitas sacolas. A seguinte pega os plásticos-filme, os brancos e mistos, a sucata, que elas chamam de caixote, e ajuda a abrir as sacolas. Não existem limites precisos na divisão de tarefas. Mesmo que cada uma delas tenha uma função definida pela posição, elas trabalham de tal forma que a maior quantidade possível de material seja aproveitada. Outras triadoras são responsáveis por pegar o PET e também os plásticos brancos e mistos que as anteriores não pegaram. Elas têm que retirar o ar que ainda existe nas garrafas e também abrir as sacolas que ainda chegam fechadas. As triadoras posicionadas no final da esteira - na chamada "rabeira", dizem que "trabalham para todo mundo", pegando os objetos que as anteriores não conseguiram pegar. 
77 Embora o grupo disponha de um conjunto de regras previamente acordadas, como a tarefa de cada posição e seu rodízio, o funcionamento desse sistema depende de uma série de ajustes dos diferentes modos com que cada triadora opera no sistema. Se a esteira impõe a mesma velocidade para todas, o modo operatório e as estratégias que cada uma desenvolve para regular sua atividade são diferentes e interferem no resultado global, o que demanda igualmente o estabelecimento de acordos tácitos $\mathrm{e}$ arranjos de forma a preservarem seus estilos. Por exemplo, quando não conseguem pegar os materiais, algumas triadoras, os empurram no sentido contrário ao movimento da esteira, na tentativa de espalhá-los e "ganhar tempo". Contudo, dependendo da frequência com que faz isso e também da forma como espalha os materiais, ela pode provocar buracos improdutivos na esteira, e assim prejudicar o desempenho da colega que atua na sua frente, do outro lado da esteira, e também daquelas que se posicionam depois dela.

78 A apropriação do trabalho só pode acontecer com o tempo, com o desenvolvimento da experiência, que passa também pelo pertencimento e pelo acesso aos saberes do coletivo de trabalho fundado, por sua vez, na cooperação (Dejours, 2012). Uma parte dos conhecimentos da triagem é transmitida pelas trabalhadoras experientes por meio de instruções e demonstrações. Os modos operatórios se regulam de acordo com a construção dos saberes coletivos, que se dá, por sua vez, na experiência adquirida ao longo das jornadas de trabalho conjunto.

Nas cooperativas, as trabalhadoras podem parar a esteira quando estão sobrecarregadas ou atrasadas no ritmo. O julgamento e a decisão de parar ou não envolvem fatores que incluem a quantidade de pessoas trabalhando naquele momento, a quantidade de material sendo processado e, especialmente, a pressão para reduzir o estoque de material ainda não triado. Isso implica desocupar o pátio, evitando cobranças da prefeitura e indisposições com a vizinhança, uma vez que o acúmulo de material aumenta a quantidade de vetores, como urubus, ratos, baratas e o mau cheiro. Estes são alguns dos fatores que justificam, muitas vezes, a perda de material que passa pela esteira sem que seja aproveitado, e acaba sendo contabilizado e aterrado como rejeito mesmo que não o seja. As triadoras mais experientes sabem que "quando a esteira tá arroiada" (apertada), é aceitável passar mais material e que não se deve mandar parar muitas vezes para não atrapalhar o processo como um todo.

80 A habilidade para solicitar, no momento certo, a parada da esteira, ou decidir o que pode ou não deixar passar, é desenvolvida na história do coletivo e requer o conhecimento da dinâmica do trabalho, suas exigências e dificuldades. A construção dessa parada envolve assim uma espécie de equalização de olhares, facultada por afinidades fabricadas no cotidiano de trabalho, que geram solidariedade e cooperação entre elas, legitimando o pedido de parada.

81 A parada para a faxina acontece sempre ao final de cada turno, momento em que a esteira é esvaziada e os materiais que requerem uma triagem fina são retriados. É o caso dos blocos de papel, livros e cadernos que devem ser desfolhados e também dos plásticos que devem ser separados por cor. Nesse momento, as triadoras que pegaram os materiais que outras deixaram passar, entregam-nos às responsáveis para que estas os depositem nos funis adequados. Acontece, às vezes, de alguma triadora jogar o material em direção à outra, que o deixou passar quando a esteira ainda estava em movimento, em vez de mantê-lo num contêiner, até o final do turno. Segundo elas, isso 
é feito quando veem que a outra consegue pegar ou para que a outra "fique esperta", nas palavras de uma triadora.

Estas admitem sentir-se constrangidas quando alguém lhes entrega os materiais que deixaram passar, mas todas sabem que um pouco sempre passa, é impossível pegar tudo. De qualquer forma, essa situação é constrangedora porque "todo mundo vê o que você deixou passar" (triadora).

As triadoras desenvolvem preferências ou afinidades para trabalhar com umas e não com outras. No caso das novatas, o incômodo de trabalhar com parceiras pouco produtivas parece ainda maior, porque a responsabilidade pelo material que passa é atribuída, geralmente, às recém-chegadas.

A exigência do trabalho cooperativo se evidencia no esforço das triadoras inexperientes se ajustarem ao modo operatório de cada grupo e das parceiras de trabalho. Elas se ligam por afinidades. Umas são mais caladas, outras gostam de conversar mais: "Tem certos assuntos que você conversa mais com umas do que com outras", afirmam as triadoras. Algumas preferem pessoas mais calmas, "mas que trabalham de verdade, não as que ficam enrolando, saindo toda hora para ir ao banheiro, deixando passar material na esteira...". Outras, sobretudo as principiantes, se queixam daquelas que trabalham muito rápido e dizem que elas são desesperadas e deixam a colega apavorada.

Evidencia-se, aqui, uma característica fundamental da atividade que diz respeito a um debate sobre valores. Este debate é ao mesmo tempo, consigo mesmo e de ordem social, ou seja, diz respeito ao "bem viver juntos" (Schwartz, 2007, p.45). O debate consigo mesmo está ligado à economia ou à racionalidade do corpo, como economizar-se, economizar a fadiga, manter os ritmos e as cadências. $O$ debate de ordem social atua como um acordeão permanente entre o global e o microscópico. A preocupação em não atrapalhar o trabalho da vizinha faz parte dos valores do "viver juntos", como afirma Schwartz (2007, p. 45. tradução livre):

Se eu creio que devo lutar, mesmo no infinitamente pequeno, nas minúcias, para tornar vivível a vida da minha vizinha, é porque eu acredito em algo como o viver juntos e porque a política para mim tem um certo valor, desde quando isto tenha um valor no nível microscópico.

O grupo constrói acordos comuns para estabelecer julgamentos acerca do grau de exigência da separação, do que se pode ou não deixar passar, da velocidade da esteira e das solicitações de paradas. Tais julgamentos se realizam com base na complexidade de elementos que envolvem a avaliação da quantidade de material em estoque naquele dia, nas exigências da prefeitura ou da vizinhança relativas ao acúmulo de resíduos, na situação econômica da cooperativa, na previsão do tempo - que interfere na possibilidade de perda do material - e nas características das trabalhadoras. Se, por exemplo, naquele grupo existem pessoas alérgicas, é aceitável deixar passar um lote de material que contenha muita poeira.

A cooperação fundada sobre acordos normativos e regras de trabalho passa por uma atividade deôntica cujos objetivos são de libertar-se, pelo menos de forma parcial, da dominação, para reapropriar-se individual e coletivamente de uma parte de autonomia, não apenas pelo gosto da liberdade, da transgressão ou da indisciplina, mas porque esta margem de autonomia é indispensável para o exercício da inteligência, para a formação das habilidades e do prazer da subversão poiética. (Dejours, 2012, pp.96-97) 
Depois de um tempo de experiência, as triadoras reconhecem os modos operatórios umas das outras - como respeitam e como transgridem as regras - o que permite que ajustes sejam feitos entre elas. Isso possibilita, como dissemos, o desenvolvimento de relações de afinidades dentro do mesmo grupo, o afeto, a confiança e as trocas de experiência sobre o trabalho e que vão além dele. Por isso, muitas não gostam de mudar de turma.

A dificuldade de "ser treinada numa turma e trabalhar em outra", como afirmam algumas triadoras, aponta a importância da interação entre os pares e da afinidade do coletivo para a realização da atividade, uma vez que a avaliação acerca dos resultados do trabalho, ou os critérios de um trabalho bem-feito, são estabelecidos pelo coletivo, que integra valores e regras do ofício produzidos ao longo da história.

por um lado, as regras são importantes para assegurar o funcionamento da associação e certa coesão do grupo, por outro, a sua aplicação exige cuidado e, em alguns casos, flexibilidade. Os catadores reconhecem que não é possível tratar todos da mesma forma e que é necessário construir arranjos que atendam, ao mesmo tempo, as necessidades do coletivo e as especificidades de cada um. Conforme relata um cooperado, "é preciso ter paciência, dar chances e orientar".

As chances e as orientações dadas aos associados levam em conta as particularidades de cada um deles. Um trabalhador de 57 anos, que atuava no lixão, está na cooperativa desde sua fundação. Os demais colegas dizem que ele "é uma pessoa difícil", que "não entende as coisas", "briga com todo mundo" e "arranja confusão". Apesar disso, reconhecem que ele traz contribuições importantes para o grupo e, por conseguinte, tentam criar maneiras de mantê-lo na cooperativa. Afirmam que não podem excluí-lo: "é preciso achar um lugar para ele".

No caso das grávidas que trabalham na esteira, quando "a barriga cresce e começa a pesar", elas podem transferir-se para a faxina, considerada mais leve pelo fato de ser possível fazer pausas e se sentar entre uma tarefa e outra. De qualquer forma, o grupo admite que "não tem regalias". Mesmo grávida, a responsável pela faxina deve manter os banheiros, a copa, a cozinha e o escritório limpos, lavar as louças, atender telefone e levar água para as pessoas que trabalham na esteira. No primeiro mês, depois de dar à luz, a cooperada ainda recebe a distribuição das sobras, como se tivesse trabalhado. Nos três meses subsequentes, ela se mantém afastada do trabalho, recebendo o benefício previdenciário. Embora seja possível ver aqui uma manifestação de solidariedade com cooperados com restrições funcionais, facilitando a regulação da carga de trabalho (ritmo, pausas, tipo de tarefas...), não se trata efetivamente de uma dádiva pura, "não existe regalia". Existe cooperação e humanidade. Nos dizeres de Marx (1983, p. 262): "Ao cooperar com outro de um modo planejado, o trabalhador se desfaz de suas limitações individuais e desenvolve a capacidade de sua espécie". Observa-se aqui que as trocas sociais entre colegas se inscrevem na história do trabalho na triagem, integrando dimensões simbólicas e afetivas. Elas não são gratuitas nem desinteressadas, mas exigem que as trabalhadoras cooperem para chegarem juntas ao objetivo comum, como na definição de Christoph Dejours (1993, p.1, tradução livre): “a cooperação são vínculos construídos pelas pessoas com o objetivo de realizar, voluntariamente, uma obra comum". 


\section{Considerações finais}

As transformações sociais que culminaram no estabelecimento do capitalismo marcaram, ademais, o surgimento da era moderna e com esta vieram os conflitos decorrentes da fragmentação da vida social. As novas formas de produção, a especialização do trabalho, as relações hierárquicas de poder, o contrato privado são algumas características das sociedades modernas, também marcadas por uma economia e uma moral de mercado e de lucro. Nesse contexto, a eficiência se apresenta como elemento fundamental do processo produtivo, enquanto solidariedade e cooperação aparecem como elementos antagônicos ou incompatíveis. Entretanto, como apontamos neste texto, o dom, a solidariedade e a cooperação estão presentes na totalidade da existência social, tanto nas sociedades modernas e contemporâneas, quanto antes, nas sociedades arcaicas.

Embora o mercado e o estado possam negar a realidade do dom através, por exemplo, das ideias de profissionalização, como vemos acontecer hoje em diferentes serviços, o dom ainda se mostra presente no interior dessas instituições, onde os valores altruístas são indispensáveis para o seu funcionamento. No caso dos catadores de materiais recicláveis, objeto de nosso estudo, as relações de cooperação se apresentam como condição para a eficiência dos processos. E essas relações não se limitam ao interior das cooperativas. Dado seu caráter técnico, e também social, elas estão presentes em todas as etapas da cadeia produtiva, em todas as instâncias, na medida em que trabalhar, além de produzir, é também da ordem do viver juntos.

Tomar parte em uma obra comum, trabalhar juntos para atingir um objetivo, estabelecer relações resultantes de vínculos de solidariedade - em que pesem os conflitos que são gerados no cotidiano - dá sentido ao trabalho e à própria existência. Em vista disso, reafirmamos a importância e o caráter incontornável da cooperação, como buscamos traduzir concretamente no trabalho das triadoras de materiais recicláveis.

\section{BIBLIOGRAFIA}

Barros, V. A., \& Silva, M. S. (2017). La créativité nécessaire dans les activités marginales. In G. Amado, J. P. Bouilloud, D. Lhuilier, \& A. L. Ulman (Orgs.), La créativité au travail (1 $1^{\mathrm{a}} \mathrm{ed}$, Vol. 1, pp. 241-258).Toulouse: Érès.

Barros, V. A., \& Pinto, J. B. M. (2008). Reciclagem: Trabalho e Cidadania. In V. H. Kemp, \& H. Crivellari (Orgs.), Catadores na cena urbana: a construção de políticas sócio-ambientais. Belo Horizonte: Autêntica.

Cattani, A. D. (2009). Emancipação social. In A. D. Cattani, J.-L., Laville, L. I. Gaiger, \& P. Hespanha (Orgs.), Dicionário internacional da outra economia (pp.175-180). São Paulo: Almedina.

Clot, Y., \& Lhuilier, D. (2010). Agir en Clinique du travail. Toulouse: Éres. 
Dejours, C. (1993). Coopération et construction de l'identité en situation de travail. Futur Antérieur 16. Retirado de http://www.multitudes.net/category/archives-revues-futur-anterieur-et/ archives-futur-anterieur/numeros-ordinaires/futur-anterieur-16-1993-2/

Dejours, C. (2012). Trabalho vivo. Trabalho e emancipação. Brasília: Paralelo 15.

Dubost, J., \& Lévy, A. (2002). Pesquisa-acção e intervenção. In J. Barus-Michel, E. Enriquez, \& A. Lévy (Orgs.), Dicionário de Psicossociologia. Lisboa: Climepsi Editores.

Faria, J. H. (2009). Gestão Participativa. Relações de Poder e de Trabalho nas Organizações. São Paulo: Atlas.

França Filho, G. C. (2013). A problemática da economia solidária: um novo modelo de gestão pública? Caderno EBAPE.BR, 11(3), 445-461. Retirado de http://www.spell.org.br/documentos/ver/ 12523/a-problematica-da-economia-solidaria--um-novo-modo-de-gestao-publica-/i/pt-br

França Filho, G. C., \& Laville, J. (2004). Economia Solidária. Uma Abordagem Internacional. Porto Alegre: Editora da UFRGS.

Gaiger, L. I. (2013). A economia solidária e a revitalização do paradigma cooperativo. Revista Brasileira de Ciências Sociais, 28(82), 211-228. http://dx.doi.org/10.1590/S0102-69092013000200013 Godbout, J. T. (1992). O Espírito da Dádiva. Lisboa: Epistemologia e Sociedade. Godelier, M. (2001). O Enigma do Dom. Rio de Janeiro: Civilização Brasileira. Houaiss, A., \& Villar, M. (2001). Dicionário Houaiss de Língua Portuguesa. Rio de Janeiro: Objetiva. Laplantine, F. (1994). Aprender Antropologia. São Paulo: Editora brasiliense.

Laville, J. (2004). Com Mauss e Polanyi: Rumo a uma Teoria da Economia Plural. In B. F., Nunes, \& P. H. Martins (Eds.), A Nova Ordem Social. Perspectivas da Solidariedade Contemporânea (pp.42-57). Brasília: Paralelo 15.

Lima, F. P. A. (1997). Noções de Organização do Trabalho. C. R. Manual Prático de L.E.R (pp. 167-189). Belo Horizonte: Health.

Lima, F. P. A. (2000). A transcendência do valor: flexibilidade, focalização, terceirização e subordinação do trabalho. Anais do encontro Nacional de Engenharia de Produção, Brasil. Retirado em 09 de setembro, 2018, de www.abepro.org.br/biblioteca/ENEGEP2000_E0053.PDF

Lima, F. P. A., \& Oliveira, F. G. (2017). Recycling and social technologies for sustainability: The Brazilian experience of wastepickers' inclusion in selective collection programs. Work, 57(3), 363-377. DOI: 10.3233/WOR-172562

Magni, A. A. C., \& Gunther, W. M. R. (2014). Cooperativas de catadores de materiais recicláveis como alternativa à exclusão social e sua relação com a população de rua. Revista Saúde e Sociedade, 23(1), 146-156. http://dx.doi.org/10.1590/S0104-12902014000100011.

Mauss, M. (1974). Ensaio Sobre a Dádiva. Forma e Razão da Troca nas Sociedades Arcaicas. In Sociologia e Antropologia (Vol. II). São Paulo: EPU.

Marx, K. (1983). o capital: crítica da economia política. São Paulo: Abril Cultural.

Martins, P. H. (2005). A sociologia de Marcel Mauss: Dádiva, simbolismo e associação. Revista Crítica de Ciências Sociais, 73, 45-66. https://doi.org/10.4000/rccs.954

Mata, C., Oliveira, F. G., \& Barros, V. A. (2017). Experiência, Atividade, Corpo: Reflexões na confluência da Psicossociologia do Trabalho e Ergologia. Psicologia em Revista, 23(1), 361-373. https://doi.org/10.5752/P.1678-9563.2017v23n1p361-373 
Moraes Neto, B. (1991). Marx, Taylor e Ford. As Forças Produtivas em Discussão (2 $2^{\mathrm{a}}$ ed). São Paulo: Editora Brasiliense.

Oliveira, F. G. (2010). Processos de Trabalho e produção de vínculo; Eficiência e Solidariedade na triagem de materiais recicláveis (Dissertação de Mestrado). Universidade Federal de Minas Gerais, Belo Horizonte, MG, Brasil.

Oliveira, F. G. (2016). Do "trabalho sujo" à bela obra: o que é triar materiais recicláveis? Um estudo em psicossociologia do trabalho (Tese de Doutoramento). Universidade Federal de Minas Gerais, Belo Horizonte, MG, Brasil.

Sato, L., Andrada, C. F., Evora, I. M. A., Neves, T. F. S., \& Oliveira, F. (2011). As tramas psicossociais da cooperação e da competição em diferentes contextos de trabalho. Arq. bras. psicol., 63, 2-14.

Schwartz, Y., \& Durrive, L. (2015). Trabalho e Ergologia II - Diálogos sobre a atividade Humana. Belo Horizonte: Fabrefactum.

Schwartz, Y. (2007). Un bref aperçu de l'histoire culturelle du concept d'activité. Activités, 4(2), 122-133. https://doi.org/10.4000/activites.1728

Sennett, R. (2012). Juntos: os rituais, os prazeres e a política da cooperação. Rio de Janeiro: Record.

Singer, P. (2002). Introdução à Economia Solidária. São Paulo: Ed. Fundação Perseu Abramo.

Tarozzi, M. (2011). o que é a Grounded Theory? Petrópolis: Vozes.

Wellen, H. (2012). Para a crítica da “Economia Solidária”. Brasil: Outras Expressões.

\section{RESUMOS}

Este texto tem como objetivo analisar as maneiras pelas quais vínculos de cooperação são construídos, como operam com a mediação da solidariedade e sua importância para garantir eficiência em empreendimentos de economia solidaria. Tais empreendimentos, definidos pela propriedade coletiva dos meios de produção estão inseridos no mundo do trabalho capitalista e nesse caso a mediação da relação solidariedade/cooperação apresenta especificidades e gera conflitos. A partir de elementos conceituais e dados analíticos de pesquisas empíricas realizadas no setor de triagem de materiais recicláveis, de dois empreendimentos de economia solidária, busca compreender os modos operatórios e estratégias desenvolvidas para regular a atividade considerando as singularidades e capacidades de trabalho diferentes, uma vez que a esteira impõe a mesma velocidade para todas as trabalhadoras. Conclui pelo caráter incontornável da cooperação tanto para a construção de formas específicas de trabalho conjunto, quanto para o estabelecimento de sociabilidades solidárias.

Este texto tiene como objetivo analizar los modos cómo se construyen los vínculos de cooperación, cómo estos operan con la mediación de la solidaridad y su importancia para garantizar la eficiencia en emprendimientos de economía solidaria. Estos emprendimientos se definen por la propiedad colectiva de los medios de producción y están insertados en el mundo del trabajo capitalista. En ese caso, la mediación de la relación solidaridad/cooperación presenta especificidades y genera conflictos. A partir de elementos conceptuales y dados analíticos de investigaciones empíricas realizadas en el sector de separación de materiales reciclables de dos emprendimientos de economía solidaria, buscamos comprender los modos operatorios y estrategias desarrolladas para regular la actividad, considerando las singularidades y capacidades de trabajo diferentes, ya que la cinta transportadora impone la misma velocidad a todas las trabajadoras. Concluimos que la cooperación tiene un carácter ineludible tanto para la 
construcción de formas específicas de trabajo conjunto, como para el establecimiento de sociabilidades solidarias.

Ce texte a pour objectif d'analyser comment se construisent les liens de coopération, comment ils opèrent par la médiation de la solidarité et quelle est leur importance pour assurer l'efficacité des projets d'économie solidaire. De telles organisations, définies par la propriété collective des moyens de production, s'inscrivent dans le monde du travail capitaliste, où la médiation du rapport solidarité/coopération présente des spécificités et entraîne des conflits. À partir d'éléments conceptuels et des données provenant d'une recherche empirique, réalisée dans le secteur du tri de matériaux recyclables de deux organisations de l'économie solidaire, nous cherchons à comprendre les modes opératoires et les stratégies développées pour réguler l'activité, en tenant compte des variations dans les singularités et les capacités de travail, puisque le tapis impose la même vitesse à toutes les travailleuses. On en conclut le caractère incontournable de la coopération, aussi bien pour la construction de formes spécifiques de travail conjoint que pour la mise en œuvre de sociabilités solidaires.

This research analyzes how cooperation links are formed, how solidarity mediates them and their importance to guarantee efficiency in solidarity economy initiatives. These initiatives are defined by collective ownership of the means of production, despite being inserted in a capitalist system. Mediating the relationship between solidarity and cooperation, in this case, becomes specific and conflicting. This project is based on conceptual elements and analytical data. The latter was obtained from empirical research in the sector of recyclable materials sorting of two solidarity economy initiatives. The present work utilizes both sources to understand the operative modes and strategies developed to regulate activities in the cooperative. In addition, the study analyzes how the companies consider the singularities and different work capacities since the activity imposes the same speed for all female workers. The conclusion is that cooperation is essential for constructing specific types of teamwork and for establishing solidarity sociabilities.

\section{ÍNDICE}

Mots-clés: Travail, coopération, solidarité, tri, économie solidaire

Palabras claves: Trabajo, cooperación, solidaridad, separación de materiales, economía solidaria Palavras-chave: Trabalho, cooperação, solidariedade, triagem, economia solidária

Keywords: Work, cooperation, solidarity, sorting, solidarity economy

\section{AUTORES}

\section{VANESSA ANDRADE DE BARROS}

Professora visitante na Universidade Federal da Paraíba

Av. Maria Elisabeth, 265/302. 45.058-180- Cabo Branco-

João Pessoa - PB

vanessa.abarros@gmail.com

\section{FABIANA GOULART DE OLIVEIRA}

Pós-doutoranda do Departamento de Engenharia de Produção da UFMG

Rua Oscar Trompowsky, 1093/31. 30441-123 - Gutierrez, Belo horizonte, MG

fabiana13maio@gmail.com 